\title{
SALT CRYSTALLISATION IN PORES: THE EFFECT OF CRYSTAL GROWTH RATE ON DAMAGE
}

\author{
SARA MANCIGOTTI \& ANDREA HAMILTON \\ Department of Civil and Environmental Engineering, University of Strathclyde, UK
}

\begin{abstract}
The phenomenon of salt crystallization is an important deterioration mechanism in building materials. Damage is caused by crystallisation pressure exerted within pores. Sodium sulfate is considered the most damaging salt, known to have two hydrated phases at ambient conditions. The metastable heptahydrate and the stable decahydrate called mirabilite $\left(\mathrm{Na}_{2} \mathrm{SO}_{4} .7 \mathrm{H}_{2} \mathrm{O}\right.$ and $\left.\mathrm{Na}_{2} \mathrm{SO}_{4} \cdot 10 \mathrm{H}_{2} \mathrm{O}\right)$. Damage is caused by mirabilite crystallisation either directly or via heptahydrate dissolution. The formation of mirabilite is induced at the top of the stone core by seeding with a crystal of mirabilite. We investigate the strain on the porous host from crystallisation, mirabilite crystal growth rate and degree of solution supersaturaiton with respect to mirabilite at the temperature of initiation. Using a thermostatted chamber we measure sample strain with an LVDT transducer and crystal growth rate through the core using thermocouples inserted at regular intervals along the samples. Mirabilite crystallisation is exothermic and we relate the heat produced to the quantitiy of crystals formed. The mirabilite-ice eutectic point occurs at c. $-3{ }^{\circ} \mathrm{C}$ and results in complete solidification of the remaining liquid phase and further damage.
\end{abstract}

Keywords: salt crystallisation, mirabilite crystal growth rate, degree of supersaturation.

\section{INTRODUCTION}

Salt crystallisation is one of the main causes of monument and building deterioration in the Mediterranean basin, and elsewhere around the world [1].

This phenomenon occurs on monuments exposed to varying environmental conditions and in different building materials, whether they are natural or artificial e.g. concrete.

Some of the world's most important monuments, such as Harappan archaeological remains at Mohenjo-Daro in Pakistan, the Sphinx in Egypt and all historical buildings in the city of Venice in Italy, are seriously affected by salt crystallisation [2].

Building damage due to natural environmental effects, such as salt crystallisation, reduce the life span of buildings and incur significant costs for surface repair [3].

Salts are ionic compounds that can be transported onto and into masonry in many ways: by capillary rise from groundwater and soil water, by rainfall and driving rain, by fog, dew and sea spray. The most commonly occurring salts are sodium chloride $(\mathrm{NaCl})$ and sodium sulphate $\left(\mathrm{Na}_{2} \mathrm{SO}_{4}\right)[4]$.

Sodium sulphate has been investigated due to its ability to cause significant damage to porous building materials. The destructive effect is caused by the growth of mirabilite $\left(\mathrm{Na}_{2} \mathrm{SO}_{4} \cdot 10 \mathrm{H}_{2} \mathrm{O}\right)$, from highly supersaturated solution, which can be produced from the dissolution of the more soluble thenardite $\left(\mathrm{Na}_{2} \mathrm{SO}_{4}\right)$ [5].

The work of Hamilton et al. [6], [7] highlighted the formation of a metastable phase, sodium sulphate heptahydrate $\left(\mathrm{Na}_{2} \mathrm{SO}_{4} .7 \mathrm{H}_{2} \mathrm{O}\right)$, that forms first when cooling supersaturated sodium sulphate solutions. According to Ostwald's rule of stages, it is more likely that mirabilite recrystallizes from the metastable phase than forms directly from solution, however mirabilite will form directly if the sample is seeded with a crystal of mirabilite and particularly if the solution/sample temperature is above $15^{\circ} \mathrm{C}$.

The rapid precipitation of mirabilite from the metastable phase produces a molar volume expansion of c. $125 \%$ and subsequent crystallisation pressure [8]. If a sufficiently large 
fraction of the pore wall is in contact with growing crystals and there is a repulsive interaction between the crystal and pore wall, damage results [9].

The aim of this paper is to measure the rate of mirabilite crystal growth and ice formation through the samples (sandstone and limestone) saturated with a 3 molal sodium sulphate solution, and measure the strain produced in the stone core.

The formation of both ice and mirabilite is exothermic and therefore measurable with thermocouples and both produce a volume expansion and damage to the stone sample. Using a new purpose-built thermo-stated chamber, we are able to detect: 1) the rate of propagation by measuring the temperature along the samples using 4 thermocouples and 2) the resulting deformation produced within the sample using an LVDT mounted on the chamber lid.

We relate the heat produced by mirabilite crystallisation to the quantity of crystals formed [10]. The mirabilite-ice eutectic point occurs at c. $-3^{\circ} \mathrm{C}$ and results in a complete solidification of the remaining liquid phase and further deformation within the sample. We quantify the strain produced by the two reactions, then we calculate the stress.

\section{EXPERIMENTAL METHODS}

Cylindrical samples (sandstone and limestone) of length $5 \mathrm{~cm}$ and diameter $2.5 \mathrm{~cm}$ are used. They are pre-drilled with three $2 \mathrm{~mm}$ diameter holes for thermocouples insertion, at a spacing of c. $10 \mathrm{~mm}$ from each other and then dried in an oven at $+100^{\circ} \mathrm{C}$ for more than 24 hours. The mass of the sample is weighed before and after capillary saturation with a 3 molal sodium sulphate solution, storing the sample with solution in an oven at $+45^{\circ} \mathrm{C}$ in a sealed bottle to avoid thenardite formation in the core. The saturated sample is then placed within a unique custom built thermostated chamber, which is filled with mineral oil at $+45^{\circ} \mathrm{C}$, to also avoid crystallisation within the sample. The chamber was specially designed and built in collaboration with Tecnopenta.r.l. (Teolo, PD, Italy). The chamber, shown in Fig. 1, is a stainless steel container of $2254 \mathrm{~cm}^{3}(14 \mathrm{~cm} \times 14 \mathrm{~cm} \times 11.5 \mathrm{~cm})$ designed to lower the sample temperature to at least $-5^{\circ} \mathrm{C}$. The chamber is equipped with 12 Peltier cells which controls the temperature using an electronic heat pump. The 12 Peltier cells are divided into three groups of four and positioned on the bottom and on the two side walls. Their cold face is in contact with the walls of the metal chamber while the hot face is in contact with a water cooled aluminium reservoir to dissipate heat.

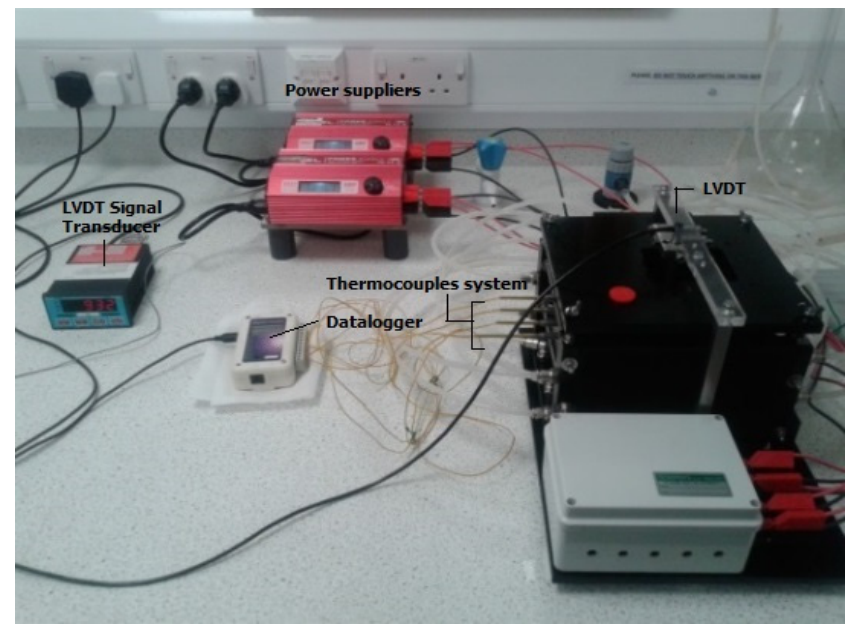

Figure 1: The thermo-stated chamber housing the sample, the thermocouples and the LVDT. 
The chamber gradually lowers the temperature of the sample placed within it from $+45^{\circ} \mathrm{C}$ to $-7^{\circ} \mathrm{C}$. To determine the propagation rate of mirabilite, the precipitation is controlled by initiating crystallisation at the top of the sample which propagates down the core. Crystallisation is initiated by seeding the core with a crystal of mirabilite at the top of the core when it reaches a known temperature. During further cooling, ice nucleates at c. $-3^{\circ} \mathrm{C}$. but nucleates randomly in the sample as it is not seeded. Both these reactions are exothermic and lead to a temperature increase within the sample of c. $2-10^{\circ} \mathrm{C}$, and produce strain within the core.

We measure the exothermic response using 3 thermocouples inserted at fixed intervals of c. $10 \mathrm{~mm}$ within the sample, while another thermocouple measures cooling of the mineral oil surrounding the sample inside the chamber. We then calculate the velocity of propagation of mirabilite crystal growth through the sample $(\mathrm{mm} / \mathrm{sec})$ and the velocity of propagation of ice $(\mathrm{mm} / \mathrm{sec})$. We can relate the temperature increase to the crystal content within the sample.

Heat transfer rate calculated confirms that the temperature rise recorded by thermocouples results from crystal propagation and not heat transfer within the sample. We calculate the thermal diffusivity of the sample and then the time it takes for the heat to travel from the top to the bottom of the core.

Sample deformation is measured using an LVDT (GT1000RA from RDP Electronics) located on the chamber lid, placed on the upper surface of the sample.

\section{PRELIMINARY RESULTS}

\subsection{Thermal analysis}

Tests have been conducted on different samples of sandstone and limestone. Their volume fraction porosity, determined by vacuum saturation, are the following: Savonnieres limestone (SA) 0.22, Berea sandstone (BE) 0.17, Euville limestone (EU) 0.13, Clipsham limestone (CP) 0.16 , Richemont limestone (RM) 0.27, Chauvigny limestone $(\mathrm{CH}) 0.14$ and Massangis Jaune Clair limestone (MJC) 0.12.Mirabilite and ice propagation rates through the cores are given in Tables 1 and 2.

We calculated the thermal diffusivity (m2/s) of the system using eqn (1).

$$
\alpha=\lambda /(\rho \times \text { hcap }),
$$

where $(\lambda)$ is the thermal conductivity $(\mathrm{W} / \mathrm{m} \cdot \mathrm{K})$ of the composite system: calcite, sodium sulphate salt and aqueous solution. Hcap is the calculated specific heat capacity of the system $(\mathrm{J} / \mathrm{K})$ and $(\rho)$ is the density of the composite system $(\mathrm{Kg} / \mathrm{m} 3)[10]$.

The time $(\mathrm{t})$ for heat transfer between thermocouples is given by eqn (2).

$$
t=\left(\alpha \times \frac{1}{(l / 1000)^{2}}\right)^{-1},
$$

where (l) is the distance in mm between each thermocouple. Results show that the time it takes for each thermocouple to detect a new temperature rise is considerably shorter than the calculated heat transfer rates for each sample. The time it takes for heat to travel from the top thermocouple to the bottom one for the Euville sample is $15.68 \mathrm{~min}$, while the crystals propagation time recorded by the same thermocouples is $28 \mathrm{sec}$. This confirms that the temperature rise detected by the thermocouples is due to crystal propagation reather then heat transfer. Fig. 2 shows the experiment conducted on an Euville limestone sample. 


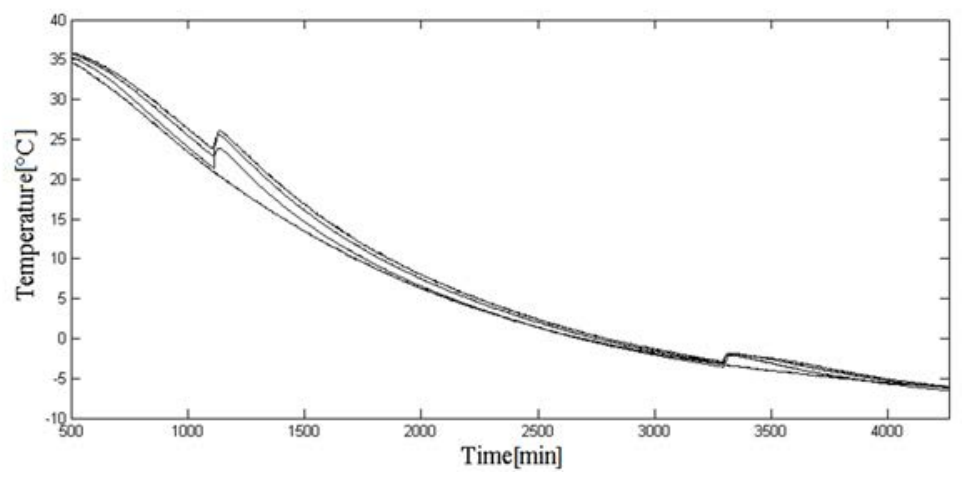

Figure 2: Measured sample temperature of an Euville limestone core, showing the top thermocouple (crosses), middle thermocouple (squares), and the bottom thermocouple (stars). All thermocouples are placed in small drilled holes, $2 \mathrm{~mm}$ deep into the stone and the temperature of the surrounding oil is shown for comparison (circles).

The mirabilite crystal propagation rate is calculated from the exothermic response detected by the thermocouples in turn as crystallisation proceeded through the core, shown magnified in Fig. 3(a). Shown on the same graph is the exothermic response from ice formation within the sample at c. $-3^{\circ} \mathrm{C}$. However the propagation direction of mirabilite crystallisation was controlled by seeding the top of the core while the direction of ice propagation was random (Fig. 3(b)) and not seeded. The propagation rate is rapid for both the reactions detected by thermocouples: $1.60 \mathrm{~mm} / \mathrm{sec}$ for mirabilite propagation and $1.25 \mathrm{~mm} / \mathrm{sec}$ for ice formation.

The temperature increase detected from the formation of mirabilite could arise from the direct crystallisation of mirabilite from solution or the conversion of heptahydrate to mirabilite. The crystallisation of the heptahydrate does not produce an exothermic response which is measureable using thermocouples. The temperature rise is directly correlated with the mass of solution within the sample, and so with the mass of mirabilite crystals forming from solution. This correlation is expressed by the eqn (3).

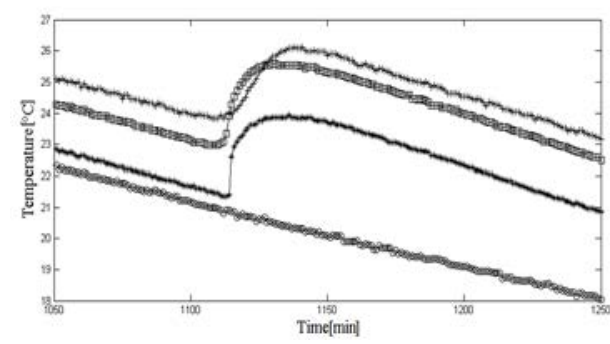

(a)

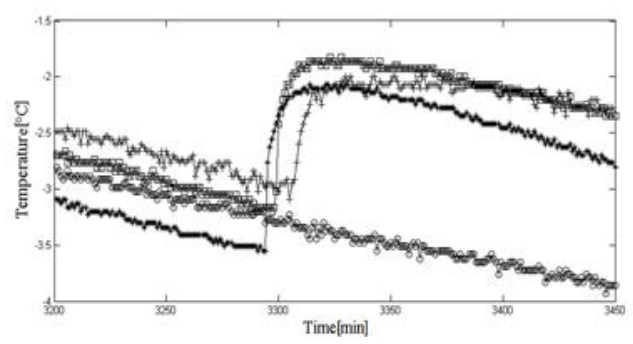

(b)

Figure 3: Magnification of the peaks in Fig. 2 related to: (a) The mirabilite formation; (b) The ice formation. 
Table 1: Preliminary results of mirabilite crystal propagation rate.

\begin{tabular}{|c|c|c|c|c|c|c|}
\hline Sample & $\mathrm{Ms}$ & $\Delta \mathrm{Tm}$ & $\Delta \mathrm{Tc}$ & $\mathrm{Tg}$ & $\mathrm{Vc}$ & $\mathrm{S}$ \\
\hline Units & $\mathrm{g}$ & ${ }^{\circ} \mathrm{C}$ & ${ }^{\circ} \mathrm{C}$ & ${ }^{\circ} \mathrm{C}$ & $\mathrm{mm} / \mathrm{sec}$ & \\
\hline BE01 & 4.89 & 2.78 & 7.15 & 21.41 & 0.82 & 1.98 \\
\hline BE02 & 3.74 & 2.10 & 5.18 & 21.76 & 1.06 & 1.93 \\
\hline BE03 & 3.56 & 1.83 & 4.40 & 21.93 & 0.73 & 1.91 \\
\hline BE04 & 3.5 & 3.68 & 4.71 & 22.64 & 3.09 & 1.81 \\
\hline CH01 & 3 & 2.06 & 4.16 & 21.62 & 0.64 & 1.95 \\
\hline $\mathrm{CH} 02$ & 2.95 & 5.85 & 6.66 & 6.96 & 4.54 & 5.84 \\
\hline $\mathrm{CH} 03$ & 3.93 & 4.26 & 7.96 & 14.53 & 1.93 & 3.32 \\
\hline CP01 & 2.98 & 5.45 & 6.54 & 15.34 & 6.8 & 3.12 \\
\hline CP02 & 2.73 & 2.35 & 5.24 & 9.23 & 1.42 & 4.93 \\
\hline CP03 & 3.02 & 4.68 & 5.85 & 15.27 & 2.83 & 3.14 \\
\hline CP04 & 3.3 & 2.06 & 4.49 & 21.86 & 2.13 & 1.92 \\
\hline CP05 & 3.16 & 2.17 & 4.33 & 21.76 & 2.46 & 1.93 \\
\hline СP06 & 4.18 & 2.81 & 4.12 & 24.28 & 1.36 & 1.60 \\
\hline EU01 & 1.5 & 1.87 & 2.23 & 20.35 & 0.7 & 2.15 \\
\hline EU02 & 4.16 & 2.49 & 4.45 & 23.83 & 1.6 & 1.65 \\
\hline MJC01 & 6.13 & 4.37 & 9.12 & 21.48 & 0.76 & 1.97 \\
\hline MJC02 & 3.18 & 6.56 & 6.85 & 10.77 & 5.55 & 4.40 \\
\hline $\mathrm{MJC} 03$ & 2.43 & 1.36 & 3.98 & 19.06 & 1.72 & 2.36 \\
\hline RM01 & 6.01 & 1.78 & 14.86 & 7.51 & 8.5 & 5.61 \\
\hline RM02 & 4.86 & 8.93 & 11.56 & 7.44 & 4.86 & 5.64 \\
\hline RM03 & 4.88 & 9.19 & $\begin{array}{l}9.88 \\
\end{array}$ & 15.37 & 3.78 & 3.12 \\
\hline RM04 & 5.95 & 7.41 & 12.40 & 15.37 & 3.09 & 3.12 \\
\hline RM05 & 5.7 & 7.55 & 11.50 & 16.11 & 2.27 & 2.95 \\
\hline RM06 & 5.85 & 7.82 & 12.17 & 15.34 & 2.83 & 3.12 \\
\hline RM07 & 5.65 & 9.83 & 13.46 & 9.09 & 8.5 & 4.98 \\
\hline RM08 & 5.31 & 7.01 & 10.70 & 15.86 & 2.27 & 3.00 \\
\hline RM09 & 5.82 & 8.02 & 11.98 & 15.62 & 4.86 & 3.06 \\
\hline RM10 & 5.9 & 8.13 & 12.06 & 15.9 & 3.09 & 2.99 \\
\hline RM11 & 5.94 & 6.91 & 9.91 & 20 & 2.27 & 2.20 \\
\hline RM12 & 6.02 & 9.31 & 12.55 & 15.41 & 5.67 & 3.11 \\
\hline RM13 & 6.09 & 10.35 & 14.41 & 10.32 & 6.8 & 4.55 \\
\hline RM14 & 6.13 & 10.71 & 15.53 & 5.61 & 8.5 & 6.47 \\
\hline RM15 & 5.81 & 9.99 & 14.18 & 7.82 & 8.5 & 5.48 \\
\hline RM16 & 5.96 & 9.08 & 14.28 & 9.37 & 6.8 & 4.88 \\
\hline RM17 & 6.15 & 8.3 & 12.9 & 15.34 & 3.78 & 3.12 \\
\hline RM18 & 5.65 & 6.02 & 9.82 & 19.27 & 1.7 & 2.33 \\
\hline RM19 & 3.02 & 4.88 & 4.66 & 20.25 & 1.7 & 2.16 \\
\hline RM20 & 6.73 & 6.12 & 9.53 & 22.07 & 1.31 & 1.89 \\
\hline SA01 & 4.45 & 4.64 & 6.80 & 20.78 & 2.17 & 2.08 \\
\hline SA02 & 4.30 & 3.48 & 7.43 & 18.84 & 1.33 & 2.40 \\
\hline SA03 & 5.08 & 3.29 & 6.26 & 22.99 & 3.5 & 1.76 \\
\hline SA04 & 4.56 & 1.35 & 6.41 & 21.76 & 1.59 & 1.93 \\
\hline
\end{tabular}

Ms: mass of solution within the sample; $\Delta \mathrm{Tm}$ : average value of the temperature increase measured by the three thermocouples in the body of each sample; $\Delta \mathrm{Tc}$ : temperature rise calculated using eqn (3); $\mathrm{T}_{\mathrm{g}}$ : temperature of growth initiation; $\mathrm{Vc}$ : mirabilite crystal propagation rate; $\mathrm{S}$ : supersaturation ratio of the salt solution within the sample. 


$$
\Delta \mathrm{T}=\left(\mathrm{H}_{\mathrm{m}} \times \mathrm{M}_{\mathrm{m}} /\left(\mathrm{m}_{\mathrm{sat}} \times \mathrm{h}_{\mathrm{cap}(\mathrm{m})}\right)\right),
$$

where hcap $(\mathrm{m})$ is the heat capacity of a system containing mirabilite, msat is the saturated mass of the sample, $\mathrm{Mm}$ is the moles of mirabilite and $\mathrm{Hm}$ is the enthalpy of mirabilite crystallisation $(-60 \mathrm{~kJ} / \mathrm{mol})[10]$, [11]. The $\Delta \mathrm{T}$ values, listed in Table $1(\Delta \mathrm{Tc})$, clearly show a good correlation with the measured temperature variations $(\Delta \mathrm{Tm})$ for most of the tested samples.

The supersaturation of the solution with respect to mirabilite, at the temperature of mirabilite formation, is given by eqn (4):

$$
\mathrm{S}=\frac{C}{C^{*}}
$$

where $C$ is the concentration of the solution, $C^{*}$ is the saturation concentration at the temperature of crystal growth initiation $\left(T_{g}\right)$ [12]. Values of $S$ and $V_{c}$, the speed of crystal growth through the sample in $\mathrm{mm} / \mathrm{s}$, are given for all the tested samples in Table 1. Fig. 4 shows a plot of supersaturation ( $\mathrm{S}, \mathrm{x}$-axis) against measured crystal growth rate through the sample $\left(\mathrm{V}_{\mathrm{c}}, \mathrm{y}\right.$-axis).

\subsection{Deformation analysis}

The sample deformation produced by salt crystallisation and ice formation was measured in order to achieve a deeper understanding of the strain/stress evolution and the resulting damage within the porous matrix.

Assuming an elastic modulus of $25 \mathrm{GPa}$ for limestone samples [13], we calculate the stress produced within the sample using eqn (5).

$$
\sigma=\mathrm{E} \times \varepsilon,
$$

where $(\varepsilon)$ is the strain produced in the sample of length $\mathrm{L}(\varepsilon=\Delta \mathrm{L} / \mathrm{L})$. The calculated stress on the core from mirabilite formation is given in Table 2, these values are within the range of the tensile strength of most sedimentary rocks (c. 3-9 MPa), which indicates the stone cores are damaged by mirabilite formation. As ice forms at the mirabilite-ice eutectic point, the contents of the core solidify, forming mirabilite and ice with no solution phase left. This should produce signigicantly more damage to the core and work is underway to collect more data at the ice-eutectic point. From ice propagation rate data, the speed of growth through the pore structure can be faster than that of mirabilite but more data is required to draw conclusions.

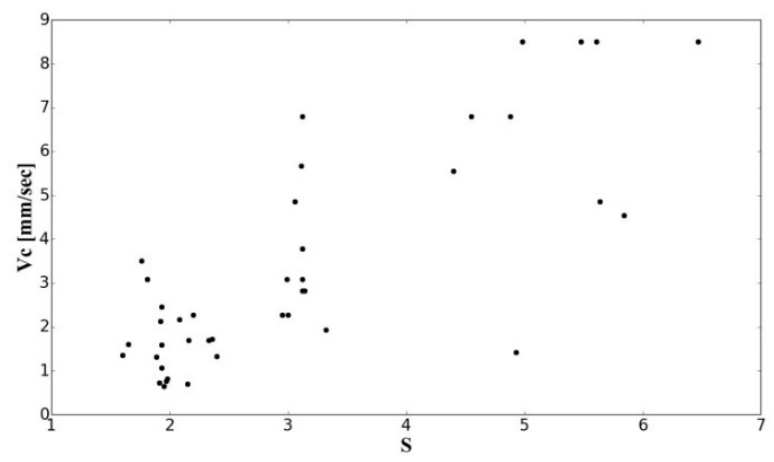

Figure 4: Core supersaturation (S, $\mathrm{x}$-axis) plotted against crystal growth rate through the core $\left(\mathrm{V}_{\mathrm{c}}, \mathrm{y}\right.$-axis). 
Table 2: Preliminary results of mirabilite crystal propagation rate and strain measured for different samples.

\begin{tabular}{|l|c|c|c|c|c|c|c|c|c|}
\hline Sample & $\Delta \mathrm{Tm}$ & $\Delta \mathrm{Tc}$ & $\mathrm{Vc}$ & $\mathrm{Ms}$ & $\mathrm{S}$ & $\mathrm{T}_{\mathrm{g}}$ & $\Delta \mathrm{Tmi}$ & $\mathrm{Vci}$ & $\sigma$ \\
\hline Unit & ${ }^{\circ} \mathrm{C}$ & ${ }^{\circ} \mathrm{C}$ & $\mathrm{mm} / \mathrm{s}$ & $\mathrm{g}$ & & ${ }^{\circ} \mathrm{C}$ & ${ }^{\circ} \mathrm{C}$ & $\mathrm{mm} / \mathrm{s}$ & $\mathrm{MPa}$ \\
\hline BE03 & 1.83 & 6.05 & 0.73 & 3.56 & 1.87 & 22.18 & 1.48 & 3.65 & - \\
\hline BE04 & 3.68 & 5.95 & 1.31 & 3.5 & 1.80 & 22.64 & - & - & 7.15 \\
\hline RM20 & 6.12 & 12.60 & 1.31 & 6.73 & 1.88 & 22.07 & 3.85 & 1.31 & - \\
\hline SA01 & 4.64 & 7.78 & 0.89 & 4.45 & 2.20 & 20.78 & - & - & 8.78 \\
\hline SA02 & 3.48 & 7.48 & 1.25 & 4.30 & 2.37 & 18.84 & - & - & 8.42 \\
\hline SA03 & 3.29 & 9.05 & 1.55 & 5.08 & 2.55 & 22.99 & - & - & 5.10 \\
\hline SA04 & 1.35 & 8.00 & 0.47 & 4.56 & 2.04 & 21.76 & 4.04 & 1.96 & 5.53 \\
\hline
\end{tabular}

$\Delta \mathrm{Tm}$ : average value of the temperature increase measured by the three thermocouples in the body of each sample; $\Delta \mathrm{Tc}$ : temperature rise calculated using eqn (3); Vc: mirabilite crystal propagation rate; Ms: mass of solution within the sample; S: supersaturation ratio of salt solution within the sample; $\mathrm{T}_{\mathrm{g}}$ : is the temperature of growth initiation; $\Delta \mathrm{T}_{\mathrm{i}}$ : is an average value of the temperature increase measured by thermocouples during ice formation; $\mathrm{V}_{\mathrm{ci}}$ : is the ice formation rate and $\sigma$ is the measured strain value for mirabilite precipitation calculated as stress.

\section{CONCLUSIONS}

Thanks to a new purpose-built experimental chamber we investigate the rate of mirabilite crystal growth and the rate of ice formation within the porous matrix and we calculate the stress from the strain measured on the stone core. Preliminary results show that the propagation rate of mirabilite crystals through the length of the core sample is very fast $(1-3 \mathrm{~mm} / \mathrm{s})$ in all the tested limestone and sandstone samples, with a rapid strain response.

Mirabilite crystals propagation rate $(\mathrm{Vc})$ shows some linear dependence on the supersaturation ratio of the salt solution, indicating growth rate through the core is closely tied to the solution supersaturation at the temperature of initiation. Further work is underway to better understand the reaction mechanism and the relationship between strain developed in the porous matrix and speed of crystal growth. The calculated stress from measured strain is close to the tensile strength of most sedimentary rocks, c. 3-9 MPa and indicates the core was damaged when mirabilite formed and further work is required to measure core strain from ice formation.

[1] Espinosa-Marzal, R.M. \& Scherer, G.W., Advances in understanding damage by salt crystallization. Accounts of Chemical Research, 43, 2010.

[2] Doehne, E. \& Price, C.A.,. Stone Conservation. An Overview of Current Research. Second Edition, The Getty Conservation Institute (Ed.): Los Angeles, CA, 2010.

[3] Moncmanova, A., Environmental factors that influence the deterioration of materials. Environmental Deterioration of Materials, ed. F. Escrig, Athenaeum Press Ltd: UK, pp. 4-21, 2007.

[4] Goudie, A.S. \& Viles, H.A., Salt Weathering Hazards, Cataclasis and DeformationBand Formation in Unconsolidated Marine Terrace Sand, John Wiley \& Sons: UK, 1997.

[5] Steiger, M. \& Asmussen, S., Crystallization of sodium sulfate phases in porous materials: The phase diagram Na2SO4-H2O and the generation of stress. Geochimica et Cosmochimica Acta, 72(17), pp. 4291-4306, 2008.

[6] Hamilton, A., Hall, C. \& Pel, L., Sodium sulfate heptahydrate: direct observation of crystallization in a porous material, Journal of Physics D: Applied Physics, 41, 2008. 
[7] Hamilton, A., Hall, C. \& Pel, L., Salt damage and forgotten metastable sodium sulphate heptahydrate: Direct observation of crystallisation in a porous material. Journal of Physics D: Applied Physics, 41, 2008.

[8] Tsui, N., Flatt, R.J. \& Sherer, G.W., Crystallization damage by sodium sulphate. Journal of Cultural Heritage, 2003.

[9] Sherer, G.W., Crystallisation in pores. Cem. Concr. Res., 29, p. 1347, 1999.

[10] Hamilton, A. \& Cimerman-Sariego, A., Measuring crystal growth propagation through porous materials: transformation of sodium sulphate heptahydrate to mirabilite, SWBSS, Limassol, Cyprus, pp. 15-22, 2011.

[11] Espinosa-Marzal R.M., Hamilton A., McNall M., Whitaker K. \& Scherer G.W., The chemomechanics of crystallization during rewetting of limestone impregnated with sodium sulphate. Journals of Material Research, Pittsburgh then Warrebdale, 26(12), pp. 1472-1481, 2011.

[12] Rodriguez-Navarro, C., Doehne, E. \& Sebastian, E., How does sodium sulfate crystallize? Implications for the decay and testing of building materials. Cement and Concrete Research, 30, 2000.

[13] Robertson, E.C. \& Geological Survey (US), Thermal Properties of Rocks, US Dept. of the Interior, Geological Survey, Books and Open-file Reports Section, 1988. 